localisation which allows access of the antibody.

In spite of the similar antigenic reaction of the coat protein, whether in the intact phage or incorporated into the cell membrane, Nozaki et al. (Nature, 259, 335; 1976) suggest that the protein conformations show substantial differences. They examined the circular diochroism spectra of intact phage (f1) and of its coat protein in aqueous solution with various detergents or dissolved in micelle-forming lysolipids. The spectrum of the protein in the intact virus is quite unlike that of other proteins in simple aqueous solution, for while it shows the peak wavelengths characteristic of an $\alpha$ helical chain, the intensities of these peaks are surprisingly different. This unusual intensity distribution can be explained by the bunching of the chromophores which will occur in the packing of more than 2,000 protein molecules into a single virus particle. With this correction, the spectrum is consistent with the entirely $\alpha$-helical conformation for the protein previously suggested by Marvin and his colleagues. The spectra of the amphiphile-solubilised protein are all similar to each other and different from that of the protein in the virus in a way which suggests less than $50 \% \alpha$-helix content. This change is not, however, consistent with a significant pant of the polypeptide having a random coil conformation and Nozaki et al. suggest that the transition may be from $\alpha$ helix to $\beta$ conformation. Such a conformation would be compatible with the observed dimeric state of the protein in detergents and with the amino acid sequence around residues 26 to 36 .

This structural change does not essentially contradict the similar antigenicity, since Wickner cites preliminary evidence that the antigenic site is in the first eight amino acid residues from the $\mathrm{N}$ terminus. In the model proposed by Marvin and Wachtel, this region of the polypeptide chain is on the surface of the virus particle and it is not the region suggested to undergo the structural transition. But this gross rearrangement of secondary structure is unique among the mechanisms so far proposed for virus assembly and the interest of this phage proteincell membrane system should encourage further study.

\section{Kelp, abalone and sea otters}

\section{Robert M. May}

Before being all but exterminated by fur traders in the 18th and 19th centuries, the sea otter (Enhydra lutris) occupied a range around the northeast rim of the Pacific Ocean from the northern Japanese archipelago, through the Aleutian Islands, and along the coast of North America as far south as Baja California. Natural populations have persisted mainly in remote parts of the original range, particularly in the Aleutians and parts of southeastern Alaska. Recently, however, with the enactment of protective legislation and the reintroduction of sea otter populations off the coasts of Oregon, Washington, British Columbia and parts of central California, the species is making a comeback along the Pacific coast of North America.

Although this fact is gratifying to conservationists, it is less pleasing to those involved with abalone fisheries. Adult sea otters in captivity have been found to eat $20-25 \%$ of their body weight daily, and benthic invertebrates (such as sea urchins or abalone) are the main component of this diet. Several studies have shown a decrease in sport and commercial abalone fisheries following the arrival of sea otters into previously unoccupied areas in California.

The dominant role played by sea otters in determining the structure and dynamics of nearshore communities is demonstrated by several recent ecological studies. Estes and Palmisano (Science, 185, 1058-1060; 1974) compared islands in the western Aleutians where sea otters have occurred naturally for at least $20-40$ years (the Rat Island group) with islands lacking otters (the Near Islands). They found many floral and faunal differences between the lower intertidal marine communities on these islands: the Rat Islands have an almost complete mat of benthic brown algae (kelp), with both sessile filter-feeding invertebrates (barnacles and mussels) and motile herbivorous invertebrates (sea urchins and chitons) being inconspicuous, small and scarce; the Near Islands are heavily grazed by dense populations of sea urchins and chitons. The density of barnacles, mussels, sea urchins and chitons, respectively, averaged around $4.9,3.8,8$, and $1 \mathrm{~m}^{-2}$ at the Rat Islands, and $1,200,720,78$, and $38 \mathrm{~m}^{-2}$ at the Near Islands.

Dayton (Fish. Bull., 73, 230-237; 1975) has followed this with a very detailed study of the competitive interactions between three kelp canopy "guilds" in a community at Amchitka Island, Alaska, in which herbivorous invertebrates have been largely removed from shallow waters by sea otters. This work confirms that sea otters are extremely important in maintaining the structure of shallow water algal communities, and tempts Dayton to the evolutionary speculation that, by reducing herbivorous preda- tion, the sea otters permit a competitive differentiation of niches whereby the several kelp species coexist.

All these people are in agreement that, as sea otters become more established along the California coast, there should be a pronounced increase in the abundance of nearshore kelp. Dayton cautions against accepting this as evidence of the "natural" order of things, and he emphasises that the onceabundant giant sea cow (Hydrodamalis gigas) must have had important consequences to the kelp populations, that undercut any present day speculation as to the evolutionary consequences of kelp competition. Indeed, Dayton conjectures, it is likely that by consuming invertebrate herbivores (particularly sea urchins) "the sea otter was indirectly responsible for the high productivity of large algae necessary to maintain the sea cow populations." This conjecture is supported by the overlap of otter and sea cow populations in the Pleistocene.

This story is typical of many, where layer after layer of complication unfolds as one seeks to elucidate the structure of the pristine ecosystem, as it was before first sea cows and then sea otters were removed. Dayton gives a general warning against drawing evolutionary morals from partially reconstructed systems, because one or more crucial species may have become extinct at a time which seems distant in human memories, but is recent on an evolutionary time scale.

\section{Glaciology's grand unsolved problem}

\section{from J. Weertman}

OVER the past two decades our understanding of the behaviour and the motion of glaciers, ice shelves, and ice sheets has progressed and increased very nicely. We know enough now to recognise a grand glaciological problem that remains to be solved. The West Antarctic Ice Sheet is this problem. Actually it is a set of inter-related problems. The base of this ice sheet over a major part of its area is 0.5 to $1 \mathrm{~km}$ below sea level. A major fraction of its bed would remain below sea level if the ice sheet were removed and isostatic rebound took place. How then did this ice sheet form? Why does it remain in existence? Is it growing or disintegrating at the present time? The ice in one half of the West Antarctic Ice Sheet is draining primarily through very fast moving ice streams into the Ross Ice Shelf. These ice streams apparently are not centred over any deep, fiord-like channels cut 